
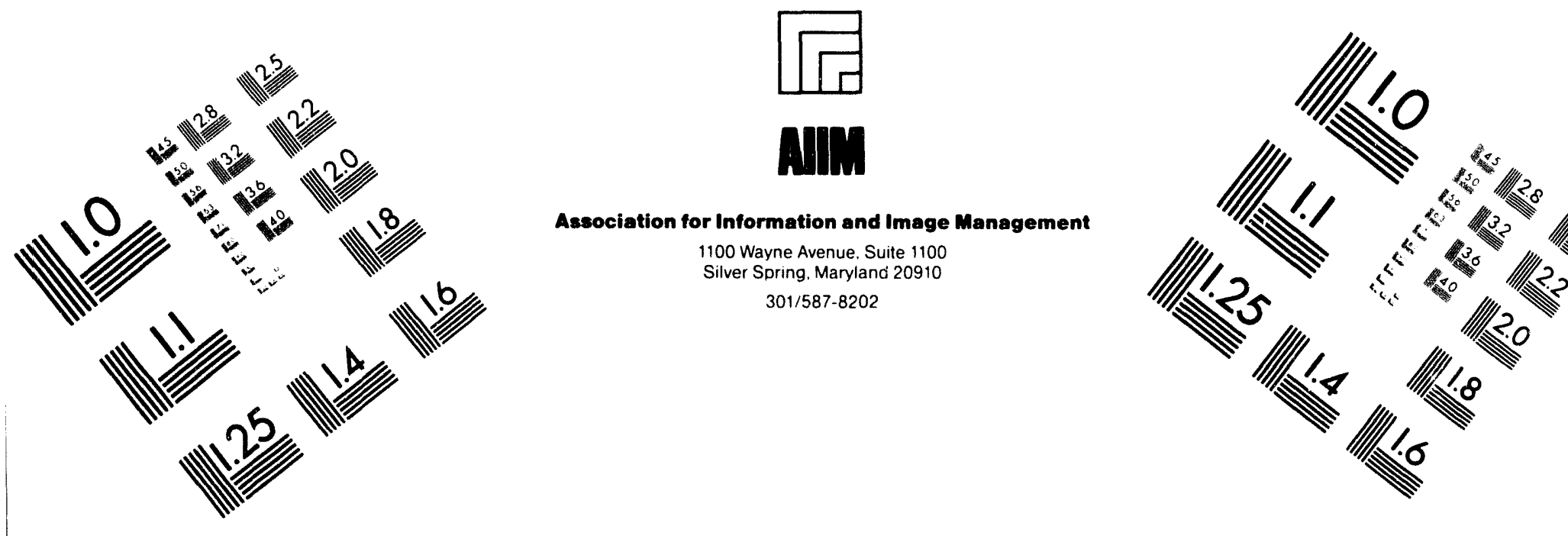

\title{
Centimeter
}

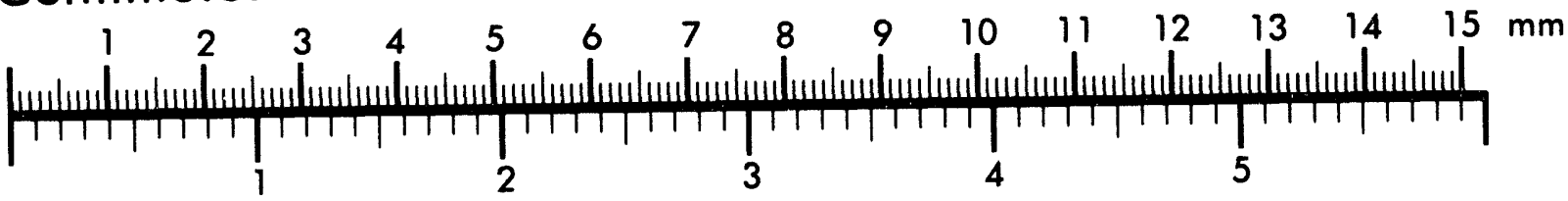
Inches
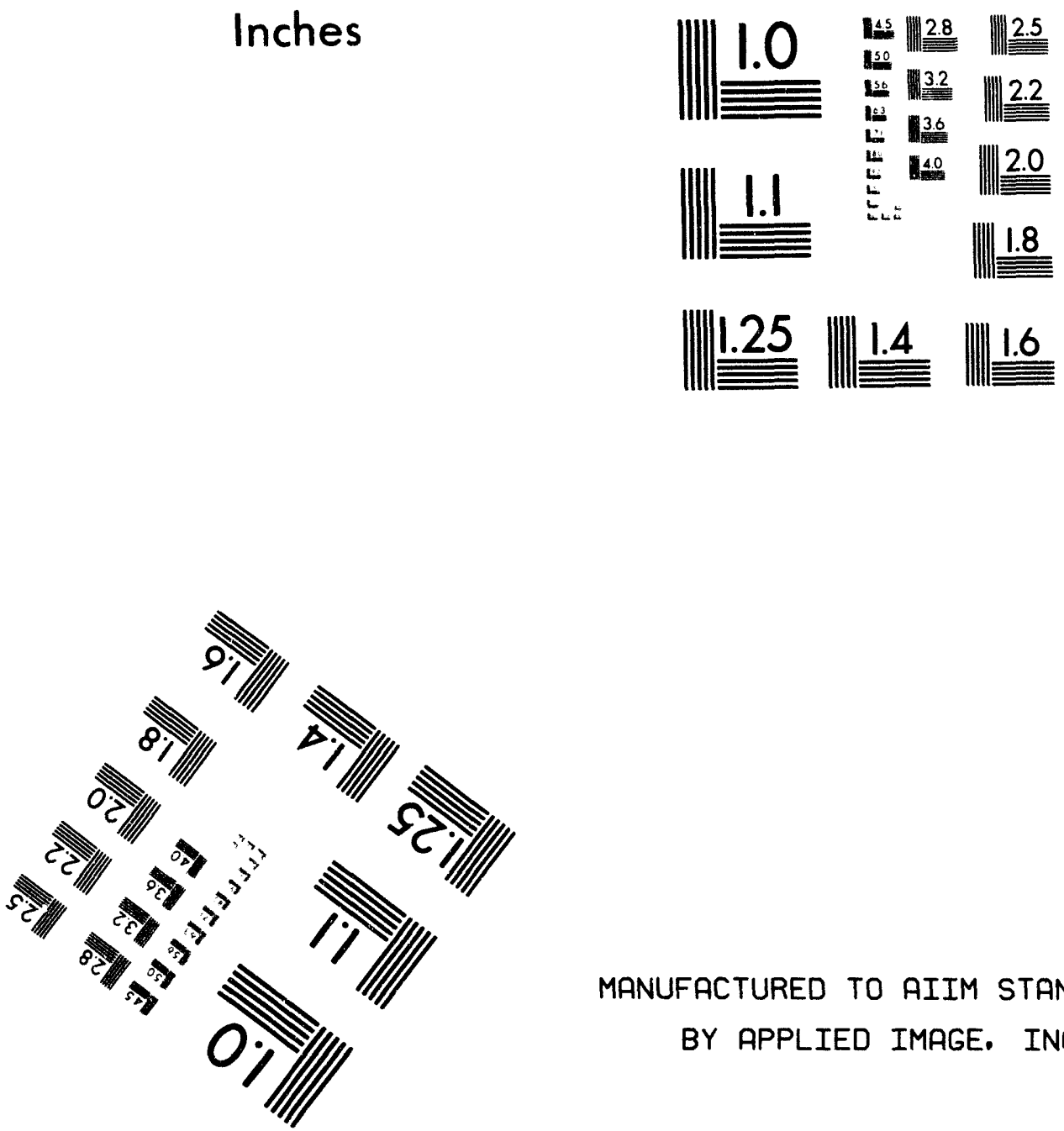

MANUFACTURED TO AIIM STANDARDS

BY APPLIED IMAGE. INC.

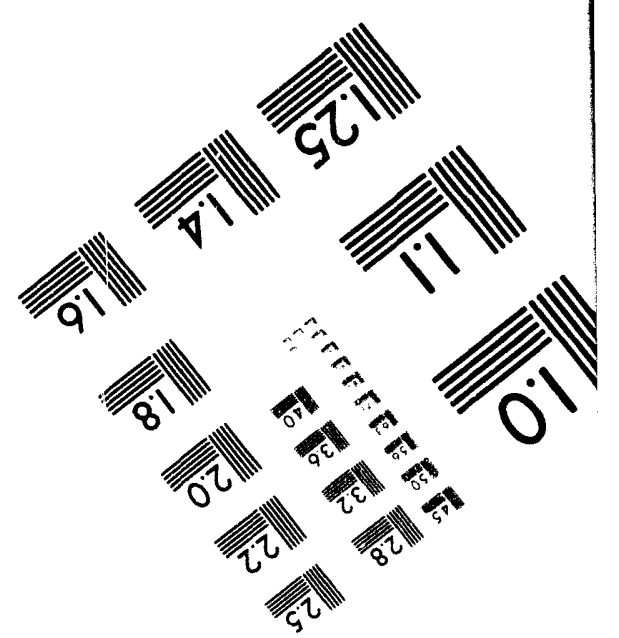



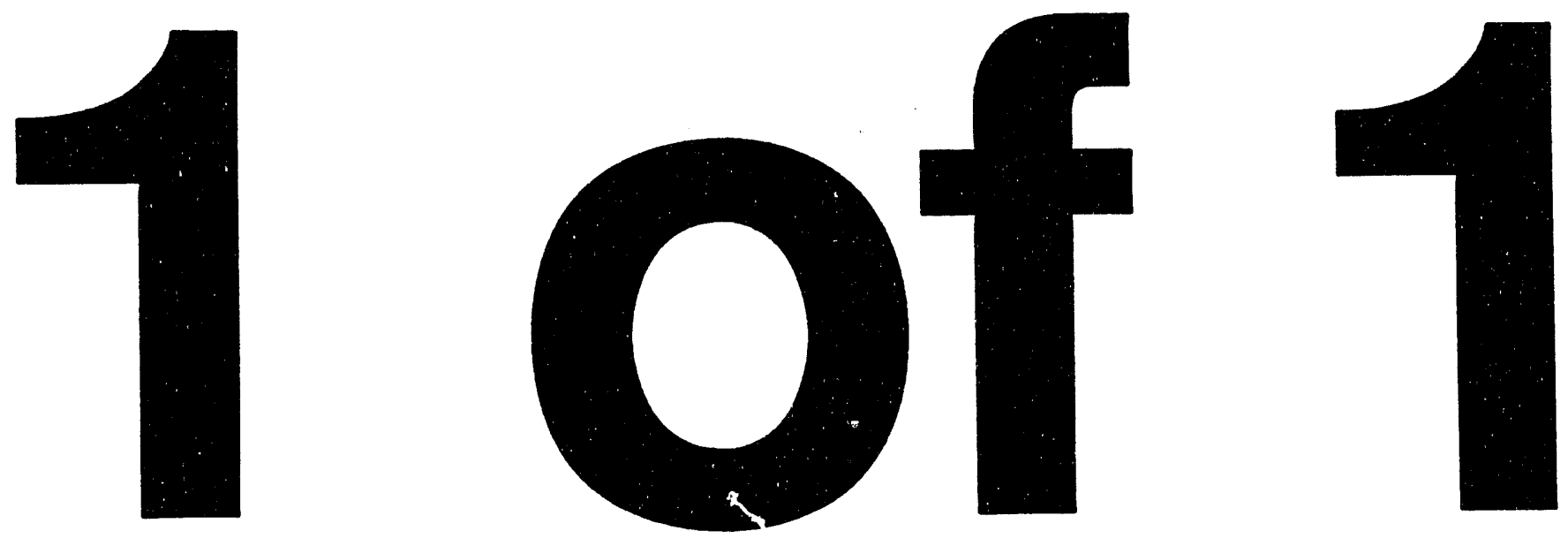


\title{
Conf. $9409168-2$
}

\section{RENEWABLE HYDROGEN PRODUCTION FOR FOSSIL FUEL PROCESSING*}

\author{
Elias Greenbaum \\ Chemical Technology Division \\ Oak Ridge National Laboratory** \\ Oak Ridge, TN 37831-6194
}

\author{
For Presentation at the \\ Coal Liquefaction and Gas Conversion. \\ Contractors' Review Conference \\ September 7-8, 1994 \\ Pittsburgh, Pennsylvania
}

\section{DISCLAIMER}

\begin{abstract}
This report was prepared as an account of work sponsored by an agency of the United States Government. Neither the United States Government nor any agency thereof, nor any of their employees, makes any warranty, express or implied, or assumes any legal liability or responsibility for the accuracy, completeness, or usefulness of any information, apparatus, product, or process disclosed, or represents that its use would not infringe privately owned rights. Reference herein to any specific commercial product, process, or service by trade name, trademark, manufacturer, or otherwise does not necessarily constitute or imply its endorsement, recommendation, or favoring by the United States Government or any agency thereof. The views and opinions of authors expressed herein do not necessarily state or reflect those of the
United States Government or any agency thereof.
\end{abstract}

\section{MASTER} Center.

${ }^{*}$ Research sponsored by the U.S. Department of Energy, Pittsburgh Energy Technology

**Managed by Martin Marietta Energy Systems, Inc., for the U.S. Department of Energy under contract DE-AC05-84OR21400. 


\author{
For Presentation at the Coal Liquefaction and Gas Conversion \\ Contractors' Review Conference \\ September 7-8, 1994 \\ Pittsburgh, Pennsylvania
}

\title{
RENEWABLE HYDROGEN PRODUCTION FOR FOSSIL FUEL PROCESSING
}

\author{
Elias Greenbaum \\ Chemical Technology Division \\ Oak Ridge National Laboratory \\ Oak Ridge, TN 37831-6194
}

\begin{abstract}
The objective of this mission-oriented research program is the production of renewable hydrogen for fossil fuel processing. This program will build upon promising results that have been obtained in the Chemical Technology Division of Oak Ridge National Laboratory on the utilization of intact microalgae for photosynthetic water splitting. In this process, specially adapted algae are used to perform the light-activated cleavage of water into its elemental constituents, molecular hydrogen and oxygen.

The great potential of hydrogen production by microalgal water splitting is predicated on quantitative measurement of their hydrogen-producing capability. These are: (1) the photosynthetic unit size of hydrogen production; (2) the turnover time of photosynthetic hydrogen production; (3) thermodynamic efficiencies of conversion of light energy into the Gibbs free energy of molecular hydrogen; (4) photosynthetic hydrogen production from sea water using marine algae; (5) the original development of an evacuated photobiological reactor for real-world engineering applications; (6) the potential for using modern methods of molecular biology and genetic engineering to maximize hydrogen production. The significance of each of these points in the context of a practical system for hydrogen production is discussed.

This program will be enhanced by collaborative research between Oak Ridge National Laboratory and senior faculty members at Duke University, the University of Chicago, and Iowa State University. The special contribution that these organizations and faculty members will make is access to strains and mutants of enicellular algae that will potentially have useful properties for hydrogen production by microalgal water splitting.
\end{abstract}




\section{Purpose}

The purpose of this project is applied research and development for the design and construction of a real-world engineering system that is capable of producing renewable hydrogen from water. The basis for further development work in this field is based on quantitative measurement of a number of important parameters and figures of merit that characterize the ability of microalgae to split water into molecular hydrogen and oxygen.

\section{The Photosynthetic Unit Size of Hydrogen Production}

Using the technique of saturating flash and individual hydrogen burst resolution, it was demonstrated (Greenbaum 1977) that the photosynthetic unit size of hydrogen evolution was comparable to and stoichiometrically related to the photosynthetic unit size of oxygen evolution. This work unambiguously demonstrated that hydrogen evolution was not a trivial side reaction of photosynthesis but, in fact, derived its reducing equivalents from the main stream of the electron transport chain of photosynthesis.

The experimental data upon which these statements are made are illustrated in Fig. 1. Figure 1 represents two experiments plotted on the same absolute axes. The hydrogen data are the absolute yield of hydrogen per saturating flash of light from the green alga Chlamydomonas reinhardtii. Four simultaneously triggered xenon flash lamps of 1-2 $\mu \mathrm{sec}$ duration were used as the light source. The oxygen data are derived from the same algae except that an electron acceptor, parabenzoquinone, was used. The main points of the data of Fig. 1 are (1) the stoichiometric ratio of hydrogen to oxygen is approximately two; and (2) the absolute values of the respective oxygen and hydrogen photosynthetic sizes are what would be expected if the source of reductant for hydrogen production was derived from the main stream of the electron transport chain of photosynthesis.

\section{The Turnover Time of Photosynthetic Hydrogen Production}

Using the technique of double-flash illumination, a direct measurement of the turnover time of photosynthetic hydrogen production was determined to be in the millisecond time range (Greenbaum 1979). This is comparable to the turnover time of oxygen evolution. The key significance of this result is that kinetics of hydrogen evolution is not rate limiting in the overall steps associated with photosynthetic hydrogen production.

The experimental data upon which these statements are made are illustrated in Fig. 2 . Figure 2 contains four different experiments in which the turnover times of molecular hydrogen production are determined for Chlamydomonas, Chlorella, Scenedesmus, and Chlamydomonas grown on a Trisacetate-phosphate medium. In these experiments, the algae were subjected to a pair of saturating light flashes of variable spacing between them. Note that on the microsecond time scale, the flash pair is unresolvable by the overall photobiochemistry of the algae. The flashes are resolved on the millisecond time scale, which is also the normal turnover time of photosynthesis. The key point of these experimental data is that the kinetic steps associated with hydrogen formation in green algae are not the limiting aspects of hydrogen production by microalgal water splitting. 


\section{Energetic Efficiency of Hydrogen Photoevolution by Algal Water Splitting}

It was demonstrated that under light-limiting conditions (i.e., in the linear low-intensity region of the light saturation curve) equivalent solar energy conversion efficiencies of $5-10 \%$ could be achieved with the green alga Chlamydomonas moewusii (Greenbaum 1988). These are the highest efficiencies for hydrogen production ever recorded and were achieved with an original experimental apparatus designed and constructed at Oak Ridge National Laboratory. Figure 3 is a schematic illustration of the experimental apparatus used for the measurements. The heart of the detection system is comprised of the oxygen and hydrogen sensors that are located downstream from the photosynthetic reaction chamber. An example of the experimental data obtained with this system for the alga Scenedesmus is illustrated in Fig. 4. Table 1 summarizes the energy conversion efficiencies obtained with the algae investigated thus far. Please note that equivalent solar energy conversion efficiencies of $10 \%$ have been obtained with the alga Chlamydomonas moewusii.

Table 1. Energy Conversion Efficiencies of Green Algae for Hydrogen and Oxygen Production

\begin{tabular}{lcc}
\hline Alga & Light on & Efficiency (PAR) \\
\hline & $n 0 .^{*}$ & $\%$ ** \\
Scenedesmus $\mathrm{D}_{3}$ & 1 & 16 \\
& 2 & 23 \\
C. reinhardtii (sup) & 1 & 13 \\
& 2 & 16 \\
& 3 & 18 \\
& 4 & 19 \\
C. reinhardtii (UTEX 90) & 5 & 21 \\
& 6 & 21 \\
C. moewusii & 7 & 18 \\
& 1 & 6 \\
& 2 & 8 \\
& 3 & 8 \\
& 1 & 24 \\
\hline
\end{tabular}

*The entries in this column correspond to the ordinal number of successive periods of illumination. The light was on for either a 3- or 4-hour period, after an equal period of darkness.

* Conversion efficiency based on absorbed photosynthetically active radiation. PAR = photosynthetically active radiation. Based on repeated measurements and calibrations, it is estimated that the experimental error in these measurements is, at most, $\pm 15 \%$. The efficiencies were computed for the rates of hydrogen evolution at the end of the period of illumination when the algae were in a steady (or nearly steady) state. 
These values of energy conversion efficiencies, obtained under strictly light-limiting conditions, are consistent with the measurements described above on the absolute photosynthetic unit sizes and turnover times.

\section{Control of Photosynthetic Reductant}

By controlling the concentration of atmospheric carbon dioxide, it is possible to improve the rates of photosynthetic hydrogen production (Cinco et al. 1993). The strategy here is to maintain sufficient $\mathrm{CO}_{2}$ such that the $\mathrm{CO}_{2} / \mathrm{HCO}_{3}$ binding site of Photosystem II is competent, while at the same time depriving the Calvin cycle pathway of its utilization of $\mathrm{CO}_{2}$. These results demonstrate that $\mathrm{CO}_{2}$ control is a rational approach to improving the rates of photosynthetic hydrogen production.

Three different light intensity/ $\mathrm{CO}_{2}$ concentrations $(58 \mathrm{ppm}, 30 \mathrm{ppm}$, and $0.8 \mathrm{ppm})$ are presented as rates of hydrogen and oxygen evolution versus time (Fig. 5). The onset of light-activated hydrogen and oxygen photoproduction is evident as is their decline when the light was turned off. Dark hydrogen evolution was subsequently observed (a phenomenon described by Gaffron and Rubin 1942 and amplified by Klein and Betz 1978). Using these data, one can obtain gas yields during light periods by integrating the peaks. For hydrogen profiles, the first half-life measures the time of decay from the maximum rate to half maximum. All yields were normalized to $1 \mathrm{mg}$ of chlorophyll (Chl) by dividing by the amount of $\mathrm{Chl}$ present for each trial (usually $0.1 \mathrm{mg}$ ).

\section{Lower $\mathrm{CO}_{2}$ Concentrations Increase $\mathrm{H}_{2}$ Yields}

The results of 11 experiments at varying carbon dioxide levels and $130 \mathrm{~W} / \mathrm{m}^{-2}$ irradiance were demonstrated (Fig. 6). This light level $r$ as chosen because it generated the highest oxygen yields at most of the $\mathrm{CO}_{2}$ concentrations used without causing photoinhibition. Oxygen yields indicated the activity of water splitting, which supplied the bulk of reductant for hydrogen synthesis. The six other light intensities exhibited patterns similar to $130 \mathrm{~W} / \mathrm{m}^{-2}$. Fifty-eight $\mathrm{ppm}$ was the highest $\mathrm{CO}_{2}$ concentration tested because $350 \mathrm{ppm} \mathrm{CO}$, which is close to normal atmospheric levels, produced similar gas yields. As the $\mathrm{CO}_{2}$ levels for algae decreased, hydrogen yields climbed slowly, reaching a maximum at $0.8 \mathrm{ppm}(11,360 \mathrm{nmol})$, where the Calvin cycle was impaired presumably because of insufficient $\mathrm{CO}_{2}$ supply. At the other extreme, $\mathrm{CO}_{2}$ levels greater than $30 \mathrm{ppm}$ allowed the Calvin cycle to dominate so that only quick bursts of hydrogen formed. The noteworthy result is the highest yield of hydiogen at $0.8 \mathrm{ppm} \mathrm{CO}_{2}$, not at $0 \mathrm{ppm}$, where the Calvin cycle would be totally deprived of external inorganic carbon.

\section{Lower $\mathrm{CO}_{2}$ Concentrations Inhibit $\mathrm{H}_{2}$ Decay}

Hydrogen rates peaked and declined in most of the 1.5 - $\mathrm{h}$ light periods. (The low light intensities are a notable exception.) First half-lives $\left(t_{12}\right)$ indicated the duration of hydrogenase activity at various $\mathrm{CO}_{2}$ concentrations. These are not implied to be the half-lives of exponential decay. They reflect the real-time loss of light-activated hydrogenase activity, due to competition with the Calvin cycle and/or depletion of alternate donor reductant pools. No permanent damage to hydrogen-forming capacity resulted from this decline, as indicated by resurgent rates of hydrogen evolution during subsequent light periods. The decay is slowest at the $0.8 \mathrm{ppm} \mathrm{CO}_{2}$ level, indicating that hydrogen photoproduction had its slowest decay at this level. The general trend showed first half-lives rising with decreasing $\mathrm{CO}_{2}$ and roughly following the behavior of hydrogen yields. 


\section{$\mathrm{O}_{2}$ Yields Decrease with $\mathrm{CO}_{2}$ Deprivation}

The decline in $\mathrm{O}_{2}$ yields can be seen with decreasing $\mathrm{CO}_{2}$ levels. The trend is downward with less carbon dioxide. The algae require $\mathrm{CO}_{2}$ (in vivo) at some level to maintain high rates of electrontransport, as indicated by oxygen production. At. $0 \mathrm{ppm}$ (pure helium) oxygen activity was $12 \%$ that at $58 \mathrm{ppm}$. However, an addition of only $0.8 \mathrm{ppm} \mathrm{CO}_{2}$, the value where $\mathrm{H}_{2}$ was maximized, more than doubled the oxygen rate. As expected, oxygen rates did not decline appreciably during the 1.5-h light periods. The significance of this result is discussed below in the Discussion section.

\section{Hydrogen to Oxygen Ratios}

Only below $10 \mathrm{ppm} \mathrm{CO}_{2}$ did hydrogen/oxygen-yield ratios approach two, in contrast to levels greater than $30 \mathrm{ppm}$, where the ratio remained less than two. These numbers approximately indicate activity of the hydrogen pathway versus the Calvin cycle. For levels $>30 \mathrm{ppm}$, carbon dioxide assimilation receives the bulk of photoproduced reductant. A yield ratio of two or more does not necessarily mean that reductant from PS I and II goes exclusively to the hydrogen pathway because of the presence of transient aiternate reductant pools (Klein and Betz 1978).

\section{Discussion}

These experiments indicate that atmospheric control of $\mathrm{CO}_{2}$ concentration is a method of controlling the fate of photosynthetic reductant. In the present case, the amount of carbon dioxide in the algal environment was titrated such that the decreasing $\mathrm{CO}_{2}$ concentration led to increasing hydrogen yields and greatest sustained rate at the $.0 .8 \mathrm{ppm}$ level. This observation can be explained by a slowing of Calvin cycle activity. With this usual sink for light-generated reductant impaired, the hydrogen pathway (through hydrogenase) can take up an increasing share of electrons. Below $10 \mathrm{ppm} \mathrm{CO}_{2}$ is where the hydrogen pathway begins to overtake the Calvin cycle, where the yield ratios $\left(\mathrm{H}_{2} / \mathrm{O}_{2}\right)$ are -2 . Conversely, low hydrogen yields (compared to oxygen) combined with short first half-lives above $30 \mathrm{ppm} \mathrm{CO}_{2}$ indicate that the Calvin cycle is the predominant pathway for photogenerated reductant in that region.

On the other hand, we can clearly see the importance of carbon dioxide for high rates of electron transport. Carbon dioxide, or its dissolved form, bicarbonate $\left(\mathrm{HCO}_{3}{ }^{-}\right)$, acts on the acceptor side of PS II as various investigators have confirmed (Eaton-Rye and Govindjee 1984; Xu et al. 1991; Jursinic and Stemler 1992; reviewed by Vermaas and Govindjee 1982). In addition to being the well known substrate for and activator of the Calvin cycle, carbon dioxide (or $\mathrm{HCO}_{3}{ }^{-}$) helps to assure normal, rapid rates of electron flow through PS II's primary $\left(Q_{A}\right)$ and secondary quinone $\left(Q_{B}\right)$ acceptors, and the plastoquinone (PQ) pool. When the concentration of $\mathrm{CO}_{2}$ was decreased, reduced efficiency of electron flow occurred, prompting the oxygen-evolving complex to slow its activity accordingly. This "bicarbonate effect" on oxygen - volving capability by depletion of $\mathrm{CO}_{2}$ (or $\mathrm{HCO}_{3}{ }^{-}$) has been discussed by Jursinic and Stemier (1992).

In considering the extent to which photosynthetic reductant can be used to produce molecular hydrogen, it is useful to ask the following question: what is the rate-limiting aspect of this process? The limiting step is definitely not the kinetics associated with the chemistry of hydrogen formation which occur on a millisecond time scale (Greenbaum 1979). This can partially be seen in the rapid 
initial bursts of hydrogen observed. The limiting step is the generally sluggish movement of electrons generated via photosynthetic water splitting and movement through the electron transport chain.

As discussed above, in a pure helium atmosphere the rate of electron transport is $12 \%$ that at $58 \mathrm{ppm}$ $\mathrm{CO}_{2}$, whereas only $0.8 \mathrm{ppm} \mathrm{CO}$ more than doubles it to $28 \%$. Although hydrogenase is an oxygen sensitive enzyme, the oxygen evolved in this system is not inhibiting it. Prior experiments have demonstrated this by titrating in oxygen upstream from the algal cell and observing its effect on hydrogenase activity. The photosynthetically produced oxygen is below this threshold.

It is concluded from these experiments that the differential affinity of $\mathrm{CO}_{2}$ to the Calvin cycle and the Photosystem II binding site is the key parameter in determining the extent to which $\mathrm{CO}_{2}$ assimilation can be bypassed while simultaneously maintaining a fully functional electron transport chain as expressed by photosynthetic oxygen evolution.

Future accomplishments will be based on advances that have been achieved in this program to date. These include the observation that it is possible to control the fate of photosynthetic reductant and improve hydrogen production by microalgal water splitting by controlling the partial pressure of atmospheric carbon dioxide. Also, development of photobiological reactors using subambient atmospheric pressure technology will continue to be studied.

\section{Evacuated Photobiological Reactors}

These results are based on U.S. Patent \#4,476,105 (Inventor: E. Greenbaum, assigned to U.S. Department of Energy). Hydrogen production in an evacuated photobiological reactor has been achieved. The significance of this result is that it greatly simplifies and improves upon previous methods that have been used for hydrogen production by microalgal water splitting. Figure 7 is a schematic illustration of the prototype evacuated photobiological reactor constructed for proof-ofprinciple experiments performed thus far. In Fig. 7 a three-way ball valve is used to connect the algal reactor chamber or calibration electrolysis cell to the hydrogen sensor. The use of an evacuated chamber eliminates the need for a sweep gas to create anaerobiosis and hydrogenase activation. The electrolysis cell is used for absolute calibration of the hydrogen sensor via Faraday's Law of Electrochemical Equivalence. Figure 8 contains the time profile of hydrogen evolution from the green alga Chlamydomonas reinhardtii along with calibration data in an evacuated atmosphere created by a conventional mechanical roughing pump.

In this task, hydrogen production will be measured using a tin-oxide gas sensitive semiconductor as the sensing element. The sensor will be located between the reactor and a mechanical vacuum pump. Hydrogen production by microalgal water splitting as a function of light intensity, temperature and other selected experimental variables will be performed. In addition, an improved version of this apparatus using a six-port sampling valve is planned. With this apparatus, both the hydrogen and oxygen evolved in the water splitting reaction will be detectable. The measurement of both gases simultaneously will provide important insight into the variability of the stoichiometric ratios of hydrogen and oxygen and information on the immediate source of reductant that provides reducing equivalents for hydrogen evolution. The bulk of these reducing equivalents are, of course, derived from water. There are, however, others that make important contributions to the overall hydrogen yields. 


\section{References}

Cinco, R., J. M. MacInnis, and E. Greenbaum. 1993. "The Role of Carbon Dioxide in Light-Activated Hydrogen Production by Chlamydomonas reinhardtii." Photosyn. Res., 38:27-33.

Eaton-Rye, J. J., and Govindjee. 1984. "A Study of the Specific Effect of Bicarbonate on Photosynthetic Electron Transport in the Presence of Methyl Viologen." Photobiochem. Photobiophys., 8:279-288.

Gaffron, H., and J. Rubin. 1942. "Fermentative and Photochemical Production of Hydrogen in Algae." J. Gen. Physiol., 26:219-240.

Greenbaum, E. 1977. "Measurement of the Photosynthetic Unit Size of Hydrogen Evolution." Science, 196:878-879.

Greenbaum, E. 1979. "The Turnover Times and Pool Sizes of Photosynthetic Hydrogen Production by Green Algae." Sol. Energ., 23:315-320.

Greenbaum, E. 1988. "Energetic Efficiency of Hydrogen Photoevolution by Algal Water Splitting." Biophys. J., 54:365-368.

Jursinic, P. A., and A. Stemler. 1992. "High Rates of Photosystem II Electron Flow Occur in Maize Thylakoids When the High-Affinity Binding Site for Bicarbonate is Empty of All Monovalent Anions or has Bicarbonate Bond." Biochem. Biophys. Acta, 1098:359-367.

Klein, U., and A. Betz. 1978. "Fermentative Metabolism of Hydrogen Evolving Chlamydomonas moewussi." Plant Physiol., 61:953-956.

Vermaas, W. F. J., and Govindjee. 1982. "Bicarbonate or Carbon Dioxide as a Requirement for Efficient Electron Transport on the Acceptor Side of Photosystem II." In Photosynthesis Vol. II (Govindjee, Ed.), 543-556. New York: Academic Press.

Xu, C., S. Taoka, A. R. Crofts, and Govindjee. 1991. "Kinetic Characteristics of Formate/Formic Acid Binding at the Plastoquinone Reductase Site in Spinach Thylakoids." Biochem. Biophys. Acta, 1098:32-40. 
Figure Legends

Fig. 1. Absolute yields of hydrogen and oxygen per saturating flash from the green alga Chlamydomonas reinhardtii. The oscillations in the oxygen yield with periodicity four correspond to the normal Joliot-Kok pattern.

Fig. 2. The turnover times of light-driven photosynthetic hydrogen production in several species of green algae. The abscissa, $\Delta t$, is the spacing between two flashes of light, each of which is of saturating intensity. The ordinate is the absolute yield of hydrogen per mole of chlorophyll per saturating flash pair. The turnover time is defined, operationally, as the point in time at which there is a 50\% increase between the initial and final steady state yields. For all experiments, the algae were anaerobically adapted in the dark prior to illumination for about 2 hours.

Fig. 3. Schematic illustration of experimental apparatus used to measure absolute light absorption and hydrogen and oxygen production by filter-paper entrapped microalgae. The chamber is an integral part of a helium-carrier flow system with connecting ports as indicated. Hydrogen and oxygen sensors are located downstream from the chamber. Absolute calibration of these sensors is achieved using Faraday's law of electrochemical equivalence with an electrolysis cell that is located in tandem with the chamber.

Fig. 4. Simultaneous photoevolution of hydrogen and oxygen from the anaerobically adapted green alga Scenedesmus $D_{3}$. The algae are irradiated with a projector lamp at normal incidence to the plane defined by the filter-paper entrapped algae. Two thour intervals of illumination an indicated. The values of hydrogen evolution used in the energy eficiency calculation were those at the end of each thour interval.

Fig. 5. Representative results of hydrogen (solid line) and oxygen (dashed line) evolution by C. reinharditi at 58, 30, and $0.8 \mathrm{ppm}$ carbon dioxide. A 2hour calibration period preceded the actual light reactions, which started at the third hour. Seven cycles of $1.5 \mathrm{~h}$ light and $1 \mathrm{~h}$ dark were performed for each of the seven irradiances (in order, from left): $227,130,64,25,6.3,24$, and $0.1 \mathrm{~W} \cdot \mathrm{m}^{-2}$ ( $\uparrow=$ light on, $\downarrow=$ light off). The peak areas, after background subtraction, represent yields of $\mathrm{H}_{2}$ or $\mathrm{O}_{2}$ and first halffives (the decay time from maximum rate to halfmaximum) were compiled for hydrogen. Other experimental conditions are described in the text.

Fig. 6. (a) Algal photoproduction of hydrogen ( $w$, dashed line) and oxygen ( $\bullet$, solid line) at various carbon dioxide levels. Shown are the trenuls of the gas yields (integration of peaks as in Fig. 2) for $1.5 \mathrm{~h}$ light periods (130 W. $\mathrm{m}^{-2}$ irradiance). All yields are normalized to $1 \mathrm{mg} \mathrm{Ch}$. Of the $11 \mathrm{CO}_{2}$ levels tested, hydrogen production is greatest near $1 \mathrm{ppm}$, but oxygen yield at this point has dropped to $30 \%$ of the value at $58 \mathrm{ppm} \mathrm{CO}_{2}$. (b) First haff-lives of decay for hydrogen rates. These measure the time it takes for the maximum $\mathrm{H}_{2}$ rate to decay to half-maximum. Shown here are the first halfilves (e) for the $130 \mathrm{~W} \cdot \mathrm{m}^{-2}$ light level, taken from the data for (a), with a solid line as the "smooth fit" through the data. Since all the hydrogen rates experienced a notable decay from an initial burst, this half-life describes how sustained the hydrogenese activity of the algae was during the $1.5 \mathrm{~h}$ of light. The peak near 1 ppm $\mathrm{CO}_{2}$ indicates that the most sustained hydrogen ovolution occurred here. (c) Hydrogen:oxygen yield ratios. These ratios $(0)$ are derived from the yields shown in (a) $\left(1.5 \mathrm{~h}\right.$ of $130 \mathrm{~W} \cdot \mathrm{m}^{-2}$ light). The trend (solid line) is toward ratios of 22 below 10 ppm $\mathrm{CO}_{2}$. 
Fig. 7. Schematic illustration of the prototype evacuated photobiological reactor for hydrogen and oxygen production by microalgal water splitting. The three-way ball valve can connect the hydrogen sensor with either the algal reaction chamber (left) or the electrolysis calibration cell (right).

Fig. 8. Time profile of hydrogen evolution from the alga Chlamydomonas reinhardtil in an evacuated photobiological reactor. Calibration data are generated by electrolysis of water using Faraday's Law of Electrochemical Equivalence to convert electrolytic current to rates of hydrogen and oxygen production. 


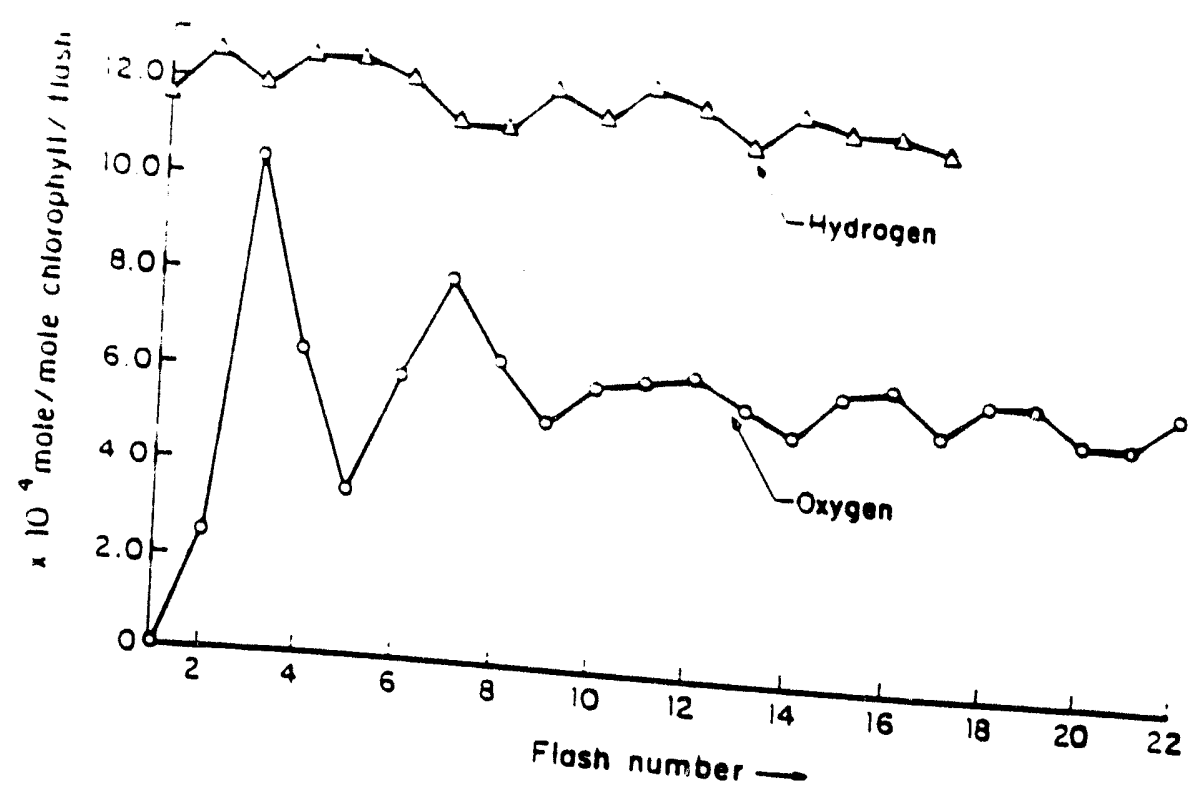

FIGURE 1
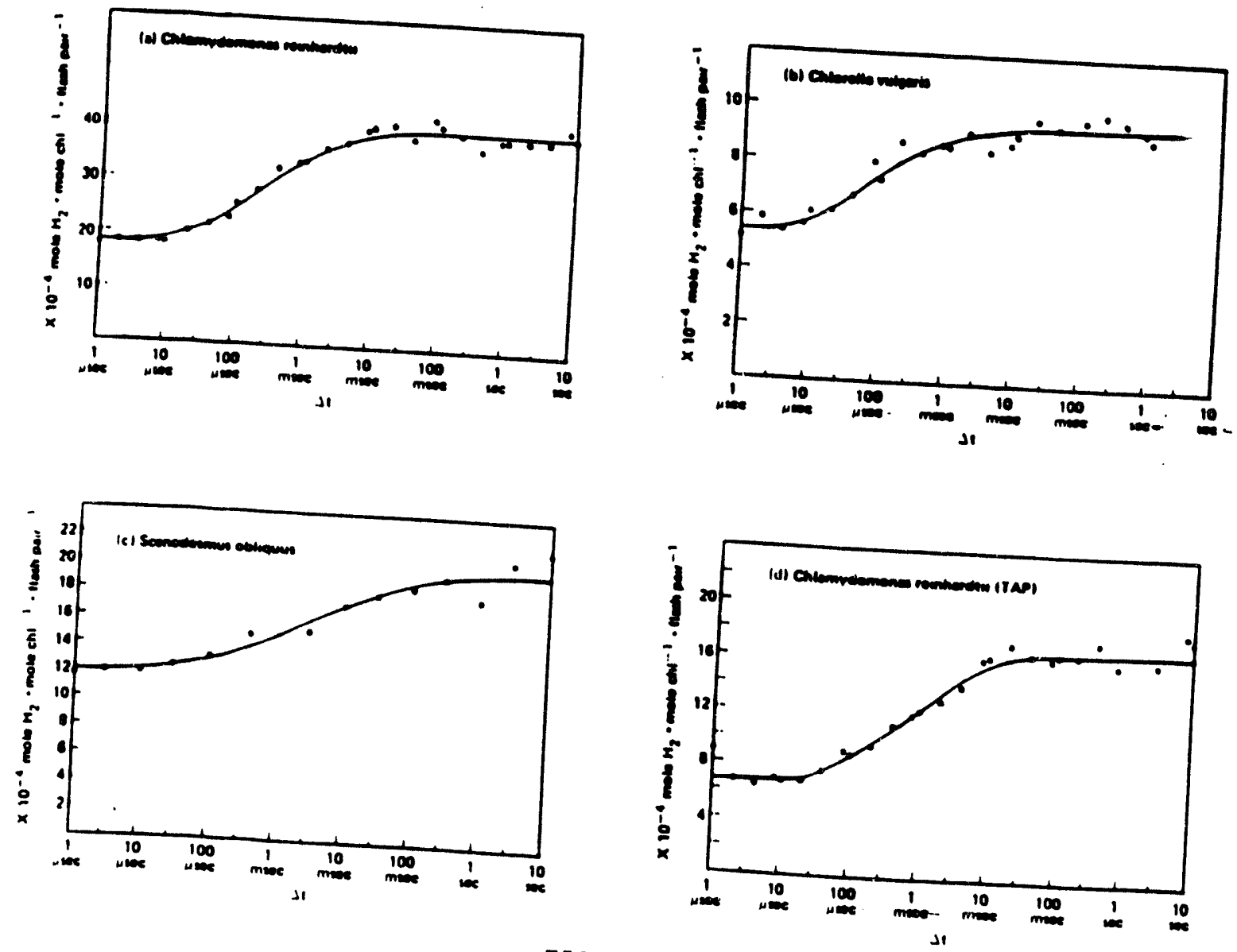

FIGURE 2 


\section{b 34 נצII}

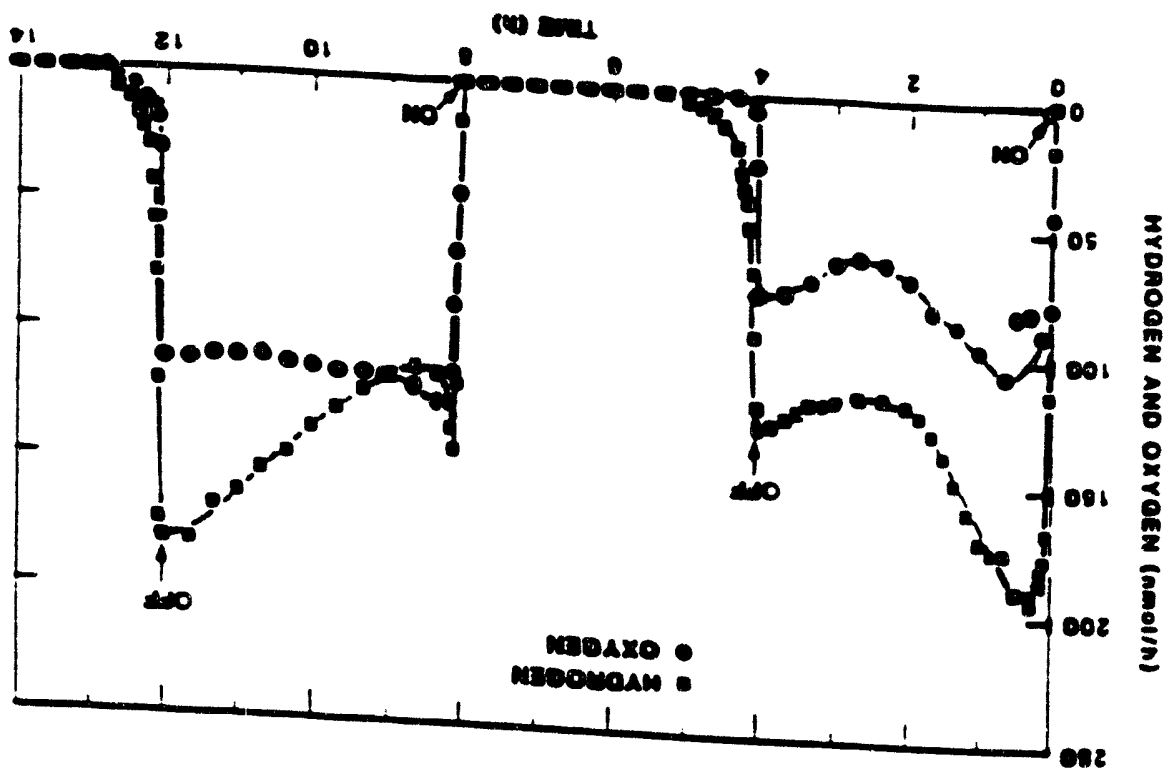

$\varepsilon$ 38กตรป

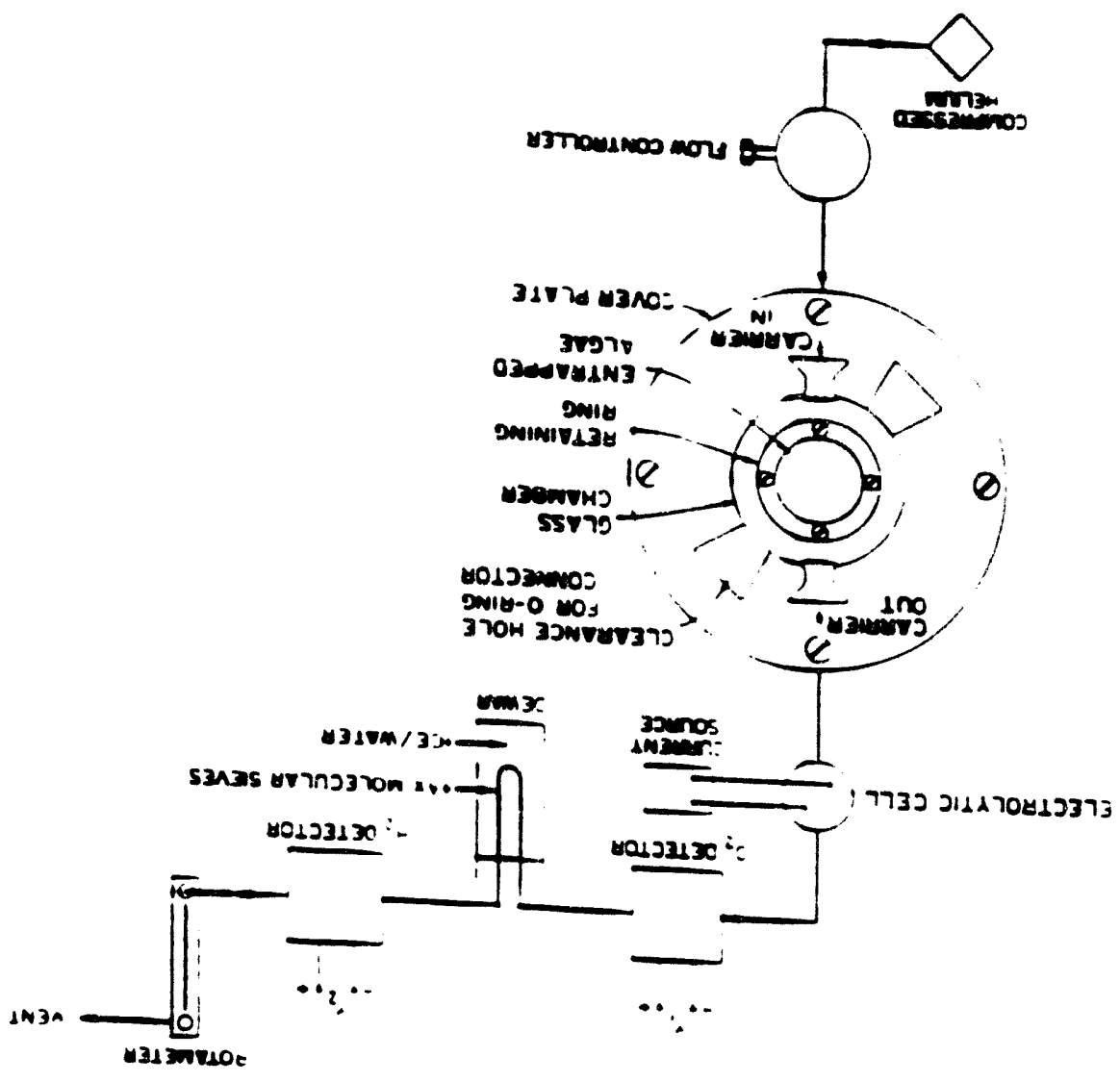




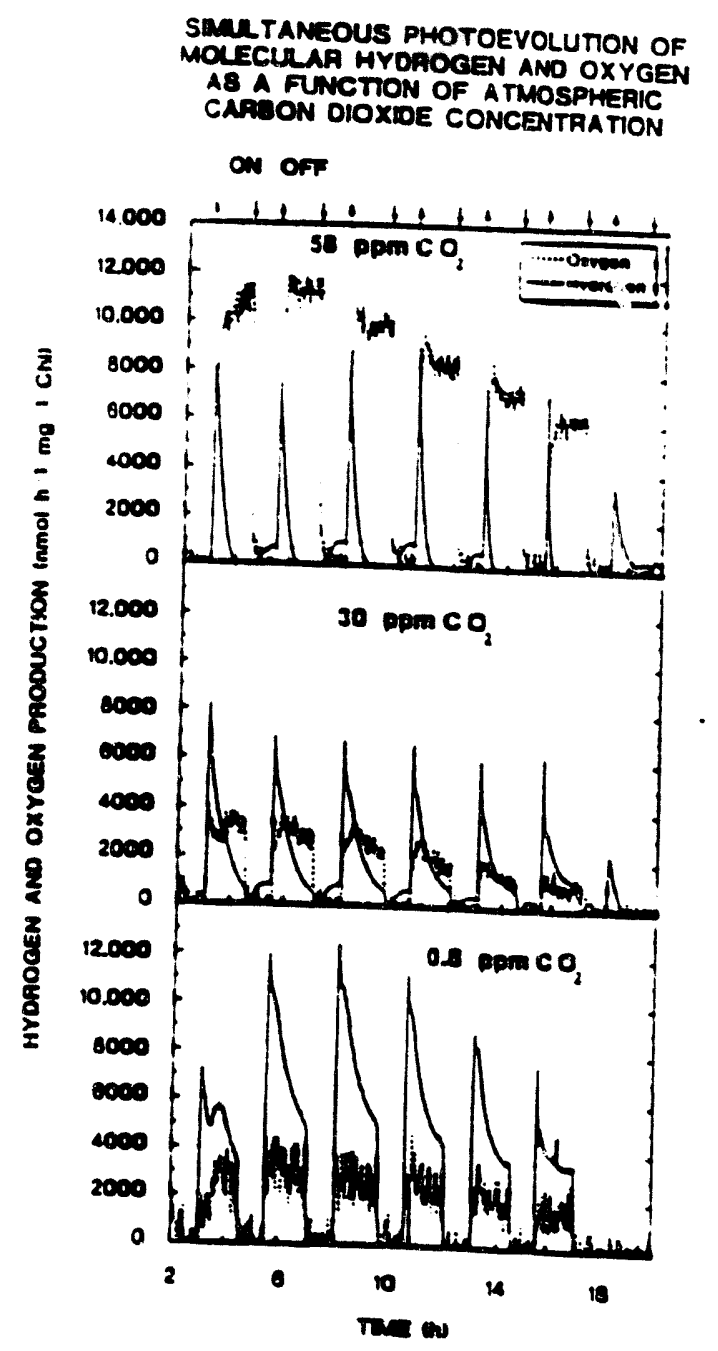

FIGURE 5

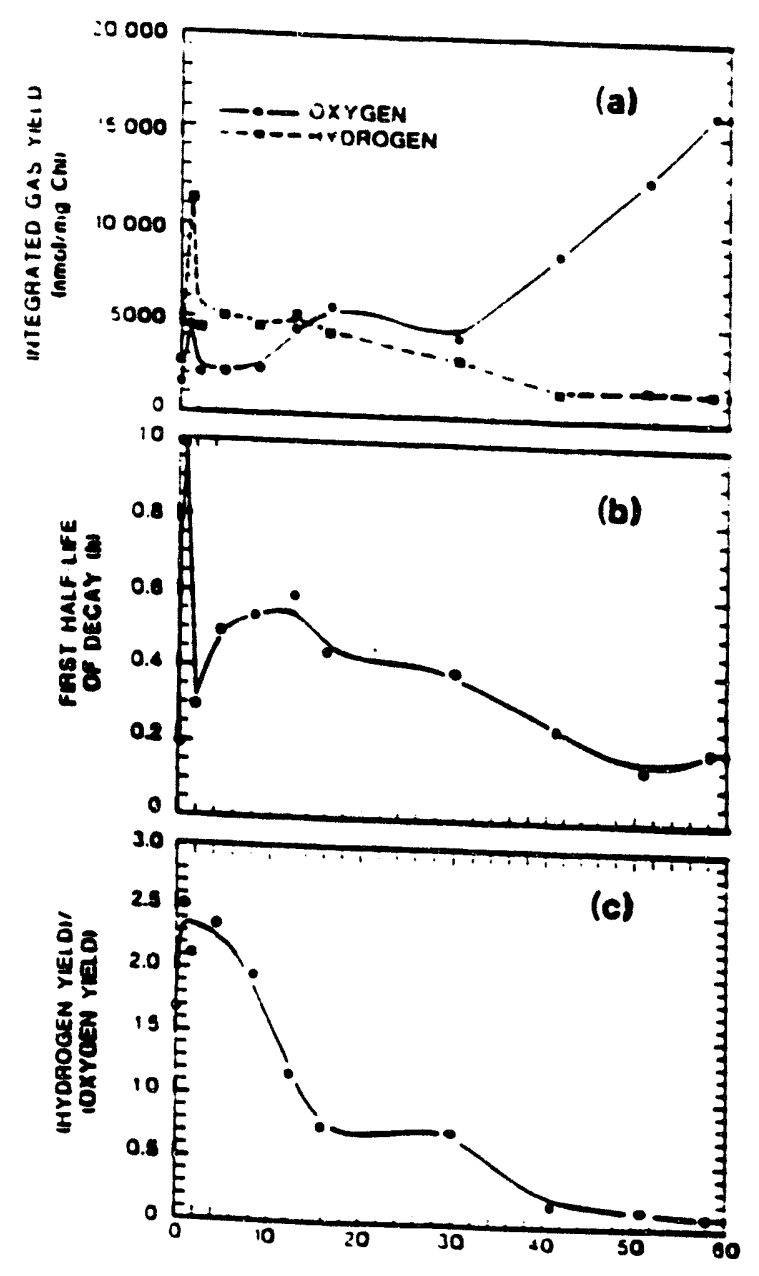

FIGURE 6 


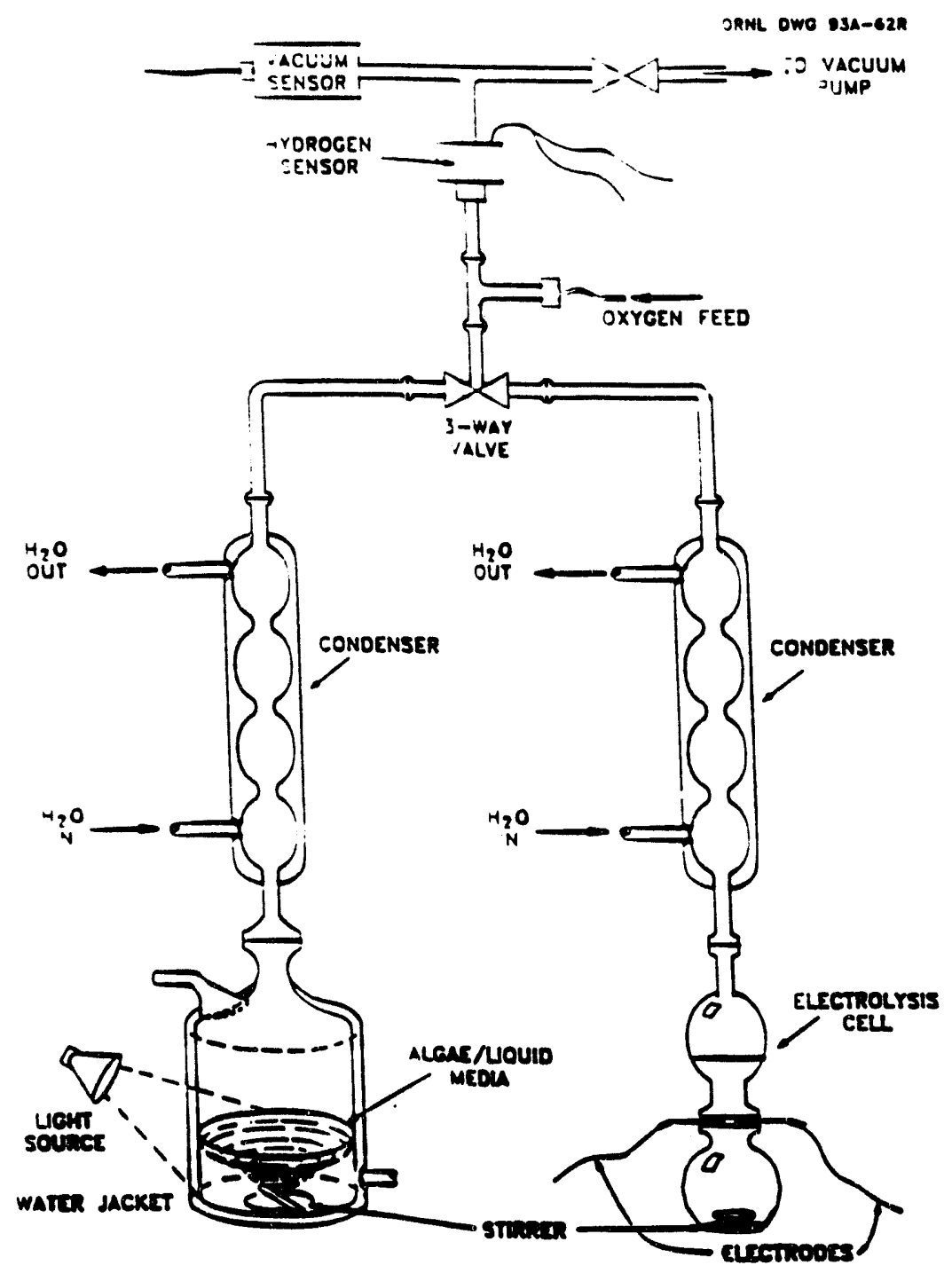

FIGURE 7

HYDROGEN PRODUCTION IN VACUO

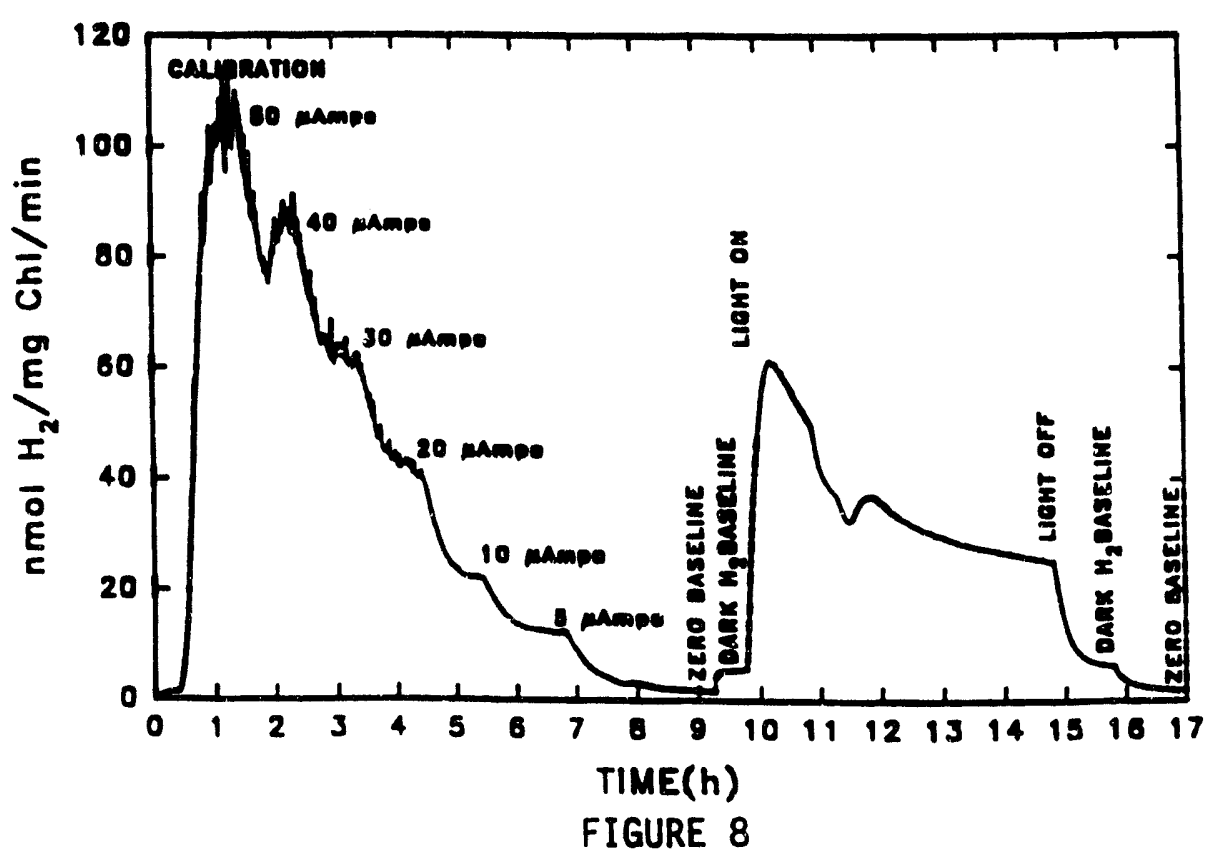



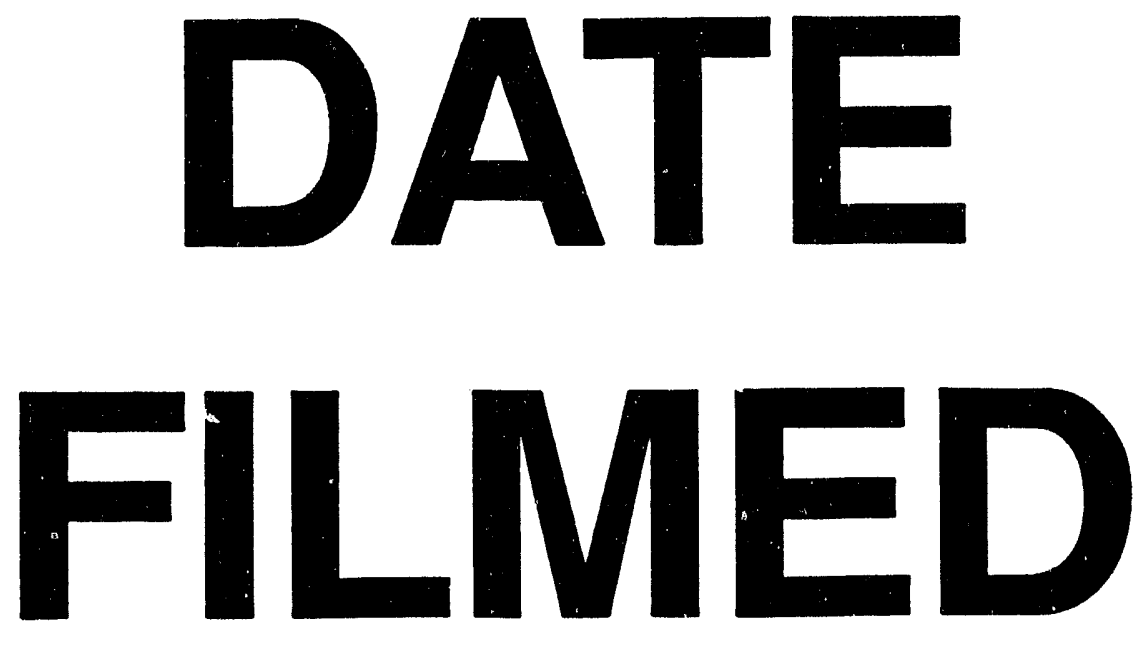

$10 / 18 / 94$
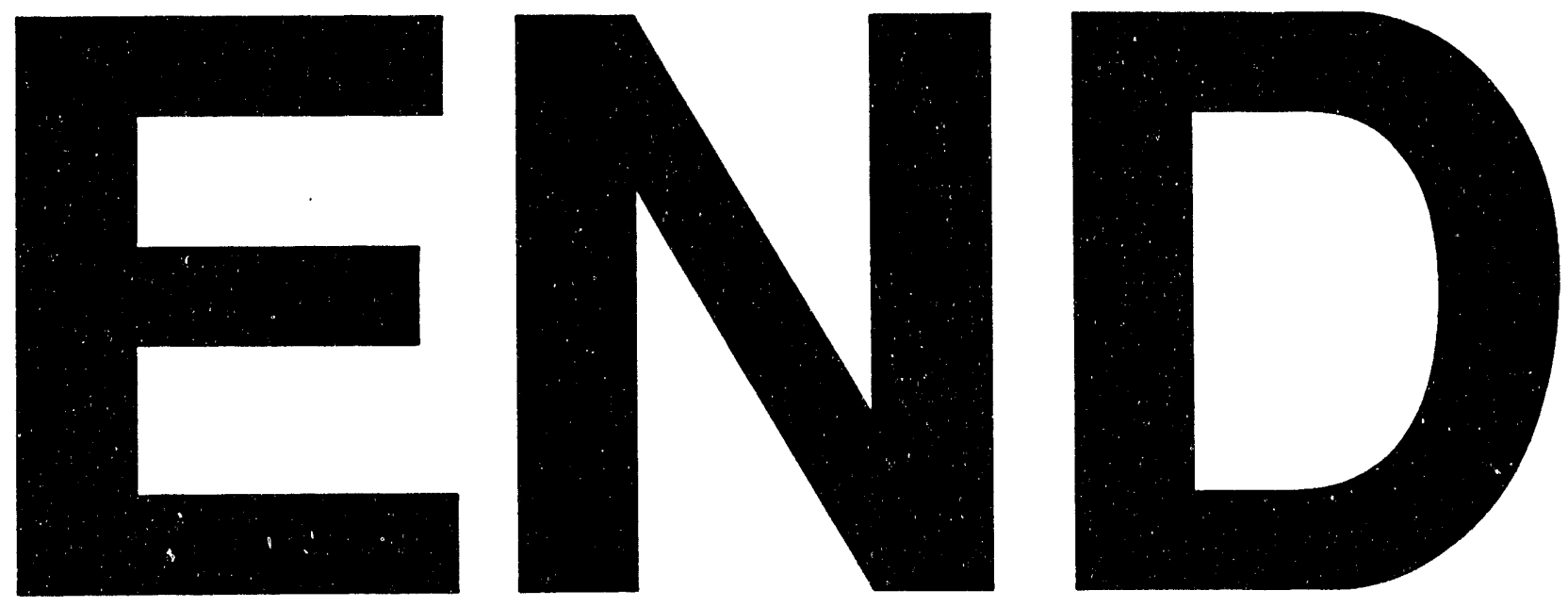
